\title{
こう配関数を用いたバングーバング制御問題の計算法
}

\author{
田、村 捷 利・市川邦彦 \\ 上智大学理工学部 東京都千代田区紀尾井町 7 \\ (昭和 45 年 1 月 8 日 受付)
}

\section{New Method Based on Gradient Function for Solving Bang-Bang Control Problems}

\author{
Katsutoshi TAmura and Kunihiko ICHIKAwA \\ (Faculty of Science and Technology, Sohia University, Chiyoda-ku, Tokyo) \\ (Recived January 8, 1970)
}

A new iterative method based on gradient function is proposed for solving bang-bang control problems. The proposed algorithm is outlined as follows. Assume any bang-bang function as an initial guess and calculate the gradient function for the control. The control function is improved succesively via the gradient function also in this method, but unlike the conventional gradient method, the time interval in which the control is improved is small and control is varied as large as admissible during that interval. Thus the improved control is again a bang-bann control.

The control after improvement is shown to give surely a less value of cost functional than before improvement. The convergent control obtained from this algorithm satisfies the local optimal condition. It is examined whether the characteristics of the gradient function with continuous control function will still hold for this case. With regard to this point, the derivation and calculation of the gradient function are also mentioned.

The usefulness of the proposed algorithm is illustrated by numerical examples. It should be remarked that the algorithm needs no assumption of switching times of optimal control function.

\section{1. まえがき}

最適制御関数*1がバングーバング形になる代表的な ものは最短時間制御であり, この最適制御関数を求め る計算法に関する研究は古くから行なわれて拉り, 線 形系の最短時間問題に関しては随伴微分方程式の初期 值を求めて最適制御関数を求めるといら方法 ${ }^{1,2)}$ など, いくつかの研究がなされている. また, 固定線形系に 対して軌道が目標点に近づくように切換光時間を変化 させてゆく跤といら研究も行なわれた．これらの研 究は系が線形であるといら条件を用いた最短時間制御 の計算法である.一般的なバングーバング制御問題に 対する計算法は Differential Dynamic Programm-

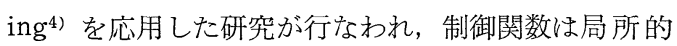
に最適条件を満足するとともに，局所的に最適な切換

*1 制御関数ということばは, 制御が時間関数であることを 表わすために用いた。
光時間を求めてゆくという研究が行なわれている.

こう配法は5 ${ }^{5)}$, , 収束の速さといら点でやや問題が あるとされている7) が, 最適制御問題を解く立場から みると理論的にも基本的なものであるだけでなく，制 御対象が線形，非線形にかかわらず，一般的な最適制 御問題を解くための有力な手法である。この手法を最 適制御関数がバングーバング制御となるような問題に 適用した場合には，バングーバング関数に収束するの にかなり多くの繰り返し計算を必要とすることがわか った ${ }^{8)}$. そこで本論では，最適なバングーバング制御 関数をこう配関数に基づいて最適な切換え時間を探索 して求めるといら計算法を提案する. 2. の問題の記 述につづいて，本論で述べるアルゴリズムの考方方と 具体的な方法を 3 . で述べ，4. ではこのアルゴリズ ムの数学的なららずけを行なった. 最後に例題によっ てこのアルゴリズムの有效性を確かめた. 


\section{2. 問 題の 記 述*2}

制御対象の運動方程式は,

$$
\left.\begin{array}{rl}
\dot{x} & =f(x, u) \\
& =f^{1}(x)+f^{2}(x) u
\end{array}\right\}
$$

麗で表わされる問題を考学る。ここに $x$ はn次元状態へ クトル, $u$ は $r$ 次元ベクトル, $f^{1}$ は $n$ 次元ベクトル 関数, $f^{2}$ は $n \times r$ マトリクスとする. $u$ には,

$$
u \in \Omega
$$

なる制限があり，指定された初期条件 $x\left(t_{0}\right)$ から出発 し, 終端条件は終端時刻を $t_{f}$ とて,

$$
t_{f}: \text { 指定, } x\left(t_{f}\right): \text { 自由 }
$$

とする. 俨価関数は,

$$
J=F\left[x\left(t_{f}\right)\right]+\int_{t_{0}}^{t_{f}} f_{0}(x) d t
$$

とする. ここに $F\left[x\left(t_{f}\right)\right] \geqq 0, f_{0}(x) \geqq 0$ であり, $f$, $f_{0}, F$ は各変数洞関して 2 回連続微分可能とする.

(1)〜 (4)式で定義される問題は最大原理》をを適用す ることによって，最適な制御はバングーバング形にな ることがわかる。

\section{3. こう配関数に基づく切換え時間探索法}

このアルゴリズムはバングーバング制御の最適な切 換え時間をこう配関数に基づいて見つけ出そうとする ものである．このアルゴリズムの具体的な流れを説明 することによって，アルゴリズムの考光方を明らかに しょう。

I . ある仮定したバングーバング制御関数 $u_{i}(t)$ を 与光, それに対してこう配関数 $g_{i}(t)$ を求める.

II. 切換光時間の修正区間をつぎのように与える.

$$
\left.\begin{array}{lll}
u_{i}(t)=h & \text { かつ } & -g_{i}(t)<0 \\
u_{i}(t)=l & \text { かつ } & -g_{i}(t)>0
\end{array}\right\}
$$

を満足する区間を修正区間とする．Fig. 1 では(a)と (b)和が修正区間である.

III. 修正区間の中で $|g(t)|$ の最大なる時刻 $t_{1}$ を取

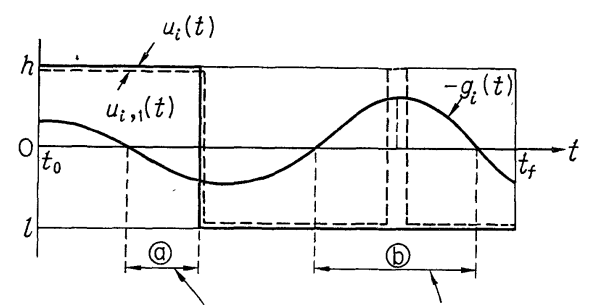

interval for which $u(t)$ may be improved

Fig. $1 u_{i}(t),-g_{i}(t)$ and $u_{i, 1}(t)$

*2 制御対象之評価関数は必ずしもここに述べた形のもので なくてもよく, 最適解がバングーバング形になるものな らなんでもよい。
り出し，区間 $\left[t_{1}-\frac{1}{2} \Delta t, t_{1}+\frac{1}{2} \Delta t\right]$ に和いて, $u_{i}(t)$ を, $u_{i}(t)$ が $h$ ならば $l$ に, lならば $h$ に修正する. この修正された制御を $u_{i, 1}(t)$ とする (Fig.1).

IV. $J\left(u_{i}\right)>J\left(u_{i, 1}\right)$ のとき, $g_{i}(t)$ は固定して抹く. $u_{i, 1}(t)$ と $g_{i}(t)$ について II, III と同じ操作を行ない $u_{i, 2}(t)$ をつくる. 以下, $J\left(u_{i, j-1}\right)>J\left(u_{i, j}\right)$ が満足さ れるかぎりつづける. $J\left(u_{i, j-1}\right)<J\left(u_{i, j}\right)$ のときは $u_{i, j-1}(t)$ を $u_{i+1}(t)$ としてIにもどる(Fig. 2).

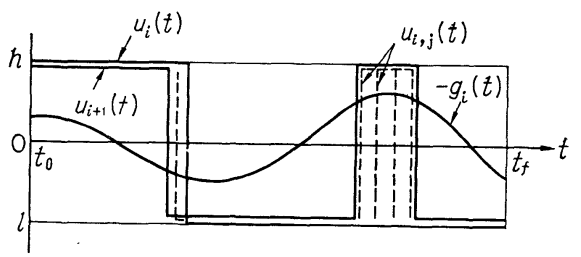

Fig. $2 u_{i}(t)$ and $u_{i+1}(t)$

以上より，このアルゴリズムの考え方はつぎのよう であることがわかる. 一般のこら配法では仮定した $u(t)$ を修正こう配関数 $\left.{ }^{6}\right)$ に比例した微小量だけ，全区 間 $\left[t_{0}, t_{f}\right]$ に和いて修正するのに対して，本手法では 修正こう配関数の絶対值の最大值をとる時刻を中心と して微小時間 $\Delta t$ だけ $|h-l|$ 修正を行ならのであ る.

このアルゴリズムを合理的なものとするだあに,

1 ) 不連続な（断片的に連 続）関数 $u(t)$ に対してこ ら配関数 $g(t)$ が計算されること, 2$) J\left(u_{i+1}\right)<J\left(u_{i}\right)$ であること，3) この計算が収束したときには局所的 最適条件が満足されていること，を明らかにしよう。

\section{4. こう配関数とアルゴリズムの収束}

(1)式に $u(t)$ を与光たときの解を $x(t), u(t)+$ $\delta u(t)$ を与えたときの解を $x(t)+\delta x(t)$ とする. この とき $\delta u(t)$ が小さいとすれば $\delta x(t)$ あ小さく, $\delta x(t)$ は,

$$
\left.\begin{array}{l}
\frac{d}{d t} \delta x=\left(\frac{\partial f}{\partial x}\right) \delta x+\left(\frac{\partial f}{\partial u}\right) \delta u \\
\delta x\left(t_{0}\right)=0
\end{array}\right\}
$$

なる微分方程式の解である。ただし， $(\partial \cdot / \partial \cdot)$ は， $x=x(t), u=u(t)$ で計算される時間関数である.こ のとき $J$ の 1 次增分 $\delta J$ は,

$$
\delta J=\left(\frac{\partial F}{\partial x}\right) \delta x\left(t_{f}\right)+\int_{t_{0}}^{t_{f}}\left(\frac{\partial f_{0}}{\partial x}(\tau)\right) \delta x(\tau) d \tau
$$

と表わされる.（7）式を，

$$
\delta J=\int_{t_{0}}^{t_{f}} g^{\prime}(t) \delta u(t) d t
$$

なる形に表わしたとき $g(t)$ を $u(t)$ に対するこう配 
関数と定義する6)。ここに'はマトリクスの転置を表 わす。

本論では $u(t)$ をバングーバング形にとっているか ら $(\partial f / \partial x)$ は不連続関数になるが，これは断片的に 連続でかつ有界であるから，(6)式の線形微分方程式 の遷移行列は連続となる ${ }^{11)}$. したがって，こう配関数 は周知のと括り ${ }^{6), 12)}$ 求めることができて,

$$
g^{\prime}(t)=-\left(\frac{\partial H}{\partial u}\right)
$$

となる.ここで, $H$ は，

$$
H=p^{\prime} f-f_{0}
$$

で定義される．またpは共状態ベクトルで，

$$
\left.\begin{array}{l}
\dot{p}=-\left(\frac{\partial f}{\partial x}\right)^{\prime} p+\left(\frac{\partial f_{0}}{\partial x}\right)^{\prime} \\
p\left(t_{f}\right)=-\left(\frac{\partial F}{\partial x}\right)^{\prime}
\end{array}\right\}
$$

によって計算される，本論では $f_{0}$ が $u$ を陽に含まな いから，こう配関数*3は，

$$
g^{\prime}(t)=-p^{\prime}\left(\frac{\partial f}{\partial u}\right)
$$

となる。

アルゴリズムの収束を考光る.まず $J\left(u_{i}\right) \geqq J\left(u_{i+1}\right)$ を証明する，そのためには $J\left(u_{i, j}\right) \geq J\left(u_{i, j+1}\right)$ を満足 するような十分小さな $\Delta t$ が存在することをいえばよ い. いいか党れば $\Delta t$ を十分小さくとれば $J\left(u_{i, j}\right) \geqq$ $J\left(u_{i, j+1}\right)$ が必ず満足されることを示せばよいことに なる. 簡単のために $u_{i}(t)$ と $g_{i}(t)$ は Fig. 1 のよう であるとする。このとき $J\left(u_{i}\right) \geqq J\left(u_{i, 1}\right)$ ならしめる $\Delta t$ の存在を証明しょう. $\delta u(t)$ を，

$$
\delta u(t)=u_{i, 1}(t)-u_{i}(t)
$$

とよって定義する・すなわち，

$$
\delta u(t)=\left\{\begin{array}{l}
0, \quad t_{0} \leqq t<t_{1}-\frac{1}{2} \Delta t \\
h-l, \quad t_{1}-\frac{1}{2} \Delta t \leqq t<t_{1}+\frac{1}{2} \Delta t \\
0, t_{1}+\frac{1}{2} \Delta t \leqq t \leqq t_{f}
\end{array}\right.
$$

$u_{i}(t)$ を与えたときの $(1)$ 式の解を $x_{i}(t), u_{i, 1}(t)$ を 与光たときのそれを $x_{i, 1}(t)$ とし， $\delta x(t)$ を，

$$
\delta x(t)=x_{i, 1}(t)-x_{i}(t)
$$

と定義する. $t_{0} \leqq t \leqq t_{1}-\frac{1}{2} \Delta t$ では $x_{i, 1}(t)=x_{i}(t)$ で あるから $\delta x(t)=0$ である。また，

$$
\delta x\left(t_{1}+\frac{1}{2} \Delta t\right)=f^{2}\left(x_{i}\left(t_{1}-\Delta t\right)\right)(h-l) \Delta t+0(\Delta t)
$$

*3 本論でいうこう配関数は impulse response function ともいわ扎ている122.
が成立するように $\Delta t$ をとると, $\delta x\left(t_{1}+\frac{1}{2} \Delta t\right)$ は $\Delta t$ 飞比例する 1 次の微小量となる. $t_{1}+\frac{1}{2} \Delta t \leqq t \leqq t_{f} \quad$ に 括いて $x_{i}(t)$ と $x_{i, 1}(t)$ は初期值が $\delta x\left(t_{1}+\frac{1}{2} \Delta t\right)+$ $0(\Delta t)$ だけちがっており, 同じ微分方程式に支配され ている。また， $\partial f / \partial x$ はこの間で連続であるから $x_{i, 1}(t)$ と $x_{i}(t)$ との差 $\delta x(t)$ は1次の微小量とな る ${ }^{10)} \cdot$ よって,

$$
\frac{d}{d t}\left(x_{i}+\delta x\right)=f^{1}\left(x_{i}+\delta x\right)+f^{2}\left(x_{i}+\delta x\right)\left(u_{i}+\delta u\right)
$$

を $x$ 関して展開して,

$$
\frac{d}{d t} \delta x=\left(\frac{\partial f}{\partial x}\right) \delta x+\left[f^{2}\left(x_{i}\right)+\left(\frac{\partial f^{2}}{\partial x}\right) \delta x\right] \delta u+0(\Delta t)
$$

を得る. (18)式の右辺第 2 項は $\delta x$ が 1 次の微小量ゆ 光, $\left(\partial f^{2} / \partial x\right) \delta x$ は $f^{2}\left(x_{i}\right)$ 飞比べて小さいので, さ らに,

$$
\begin{aligned}
\frac{d}{d t} \delta x & =\left(\frac{\partial f}{\partial x}\right) \delta x+f^{2}\left(x_{i}\right) \delta u+0(\Delta t) \\
& =\left(\frac{\partial f}{\partial x}\right) \delta x+\left(\frac{\partial f}{\partial u}\right) \delta u+0(\Delta t)
\end{aligned}
$$

と変形される. したがって $\delta u(t)$ を(14) 式のように 与えても $\delta x$ は(19)式の線形微分方程式にしたがうこ とがいえた、よって前章までの議論が適用できて，

$$
\begin{aligned}
& J\left(u_{i, 1}\right)-J\left(u_{i}\right)=\int_{t_{0}}^{t_{f}} g^{\prime}(t) \delta u(t) d t \\
& \quad=\operatorname{sgn}\left(-g\left(t_{1}\right)\right)(h-l) g\left(t_{1}\right) \Delta t+0(\Delta t) \\
& =-\left|g\left(t_{1}\right)\right|(h-l) \Delta t+0(\Delta t)
\end{aligned}
$$

が成立し， $\Delta t$ を十分小さくとれば $J\left(u_{i}, 1_{1}\right)-J\left(u_{i}\right)$ $\leq 0$ なることがい光る.

さて，このアルゴリズムが終わるのは（5)式で与兄 られる修正区間がなくなるとき，すなわち( 5 )式が完 全に満足されなくなるときである。したがって，この アルゴリズムが終わるのは,

$$
\left.\begin{array}{lll}
u(t)=h & \text { かつ } & -g(t) \geqq 0 \\
u(t)=l & \text { かつ } & -g(t) \leqq 0
\end{array}\right\}
$$

が満足されるときであり，最急傾斜法による局所的最 適条件 $[g(t)]_{\mathrm{mod}}=0$ と一致している.

\section{5. 数値計算のフローチャート}

数值計算のフローチャートは Table 1 のようにな る。

\section{6. 例 題}

\section{$6 \cdot 1$ 例 題 1}

このアルゴリズムの有効性を明らかにするために， 
Table 1 Frow chart of the Algorithm

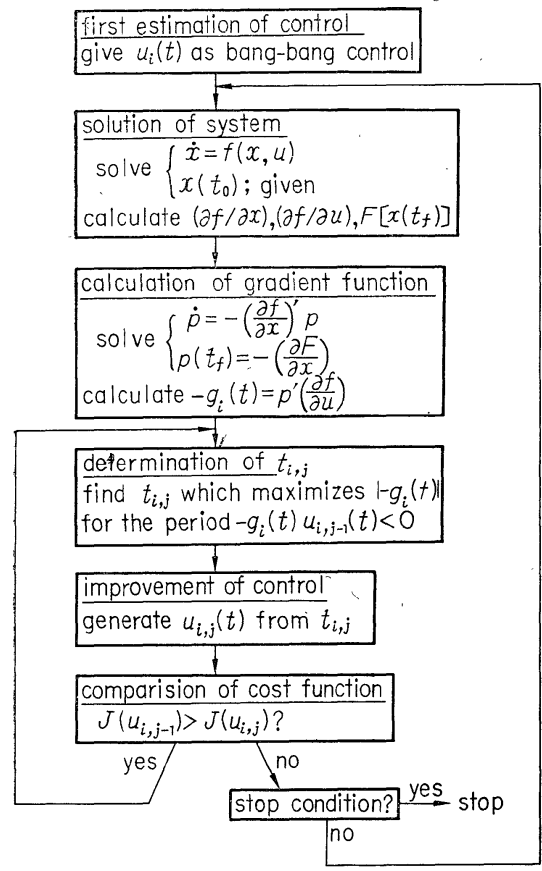

まず，解析的に解くことができる問題を本手法の手順 飞したがって解くことにする。制御対象は，

$$
\dot{x}_{1}=x_{2}, \quad \dot{x}_{2}=u
$$

で与えられ，制御 $u$ には $|u| \leqq 1$ なる制限があるとす る. 評価関数は,

$$
J=5 x_{1}{ }^{2}\left(t_{f}\right)+5 x_{2}^{2}\left(t_{f}\right)
$$

で与えられ，終端条件を

$$
t_{f}=2.0, x_{1}\left(t_{f}\right), x_{2}\left(t_{f}\right) \text { 自由 }
$$

とする. 初期条件 $x_{1}(0)=1.0, x_{2}(0)=0$ 加出発す る最適解を゙求める.

こう配関数を求めるための共状態べクトルは,

$$
\left.\begin{array}{l}
\dot{p}_{1}=0, p_{2}=-p_{1} \\
p_{1}\left(t_{f}\right)=-10 x_{1}\left(t_{f}\right), \quad p_{2}\left(t_{f}\right)=-10 x_{2}\left(t_{f}\right)
\end{array}\right\}
$$

で与党られ，解は，

$$
\left.\begin{array}{l}
p_{1}=-10 x_{1}\left(t_{f}\right) \\
p_{2}=10 x_{1}\left(t_{f}\right)(t-2.0)-10 x_{2}\left(t_{f}\right)
\end{array}\right\}
$$

したがって，こう配関数は，

$$
g(t)=-10 x_{1}\left(t_{f}\right)(t-2.0)+10 x_{2}\left(t_{f}\right)
$$

と得られる.

制御 $u$ の最初の推定を $u_{1}(t)=1.0,0 \leqq t \leqq 2.0$ と与 える・このとき,

$$
\left.\begin{array}{l}
x_{1}=\frac{1}{2} t^{2}+1, \quad x_{2}=t \\
x_{1}\left(t_{f}\right)=3, x_{2}\left(t_{f}\right)=2
\end{array}\right\}
$$

を得る。よって,

$$
-g_{1}(t)=30 t-80
$$

となる.このとき $u_{1}(t)$ と $g_{1}(t)$ を Fig. 3 に示す.

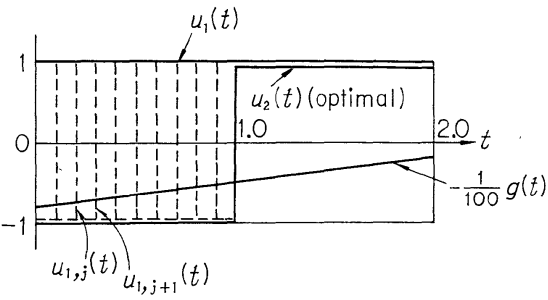

Fig. $3 u_{1}(t),-g_{1}(t)$ and $u_{2}(t)$ (optimal) in example 1

Fig. 3 から $u_{1, j}(t)$ は Fig. 3 に点線で示したように, $t=0$ のほうよりつぎつぎに,

$$
u_{1, j}(t)\left\{\begin{array}{rl}
-1 & 0 \leqq t<j \Delta t \\
1 & j \Delta t \leqq t \leqq 2.0
\end{array}\right.
$$

となることがわかる，このとき解は，

$$
\begin{aligned}
0 \leqq t & <j \Delta t \\
x_{1} & =1-\frac{1}{2} t^{2}, \quad x_{2}=-t \\
j \Delta t \leqq & \leqq 2.0 \\
x_{1} & =\frac{1}{2} t^{2}-j \Delta t \cdot t-\left(1-\frac{1}{2}(j \Delta t)^{2}\right) \\
x_{2} & =t-j \Delta t
\end{aligned}
$$

評洒関数値は,

$$
\left(u_{1, j}\right)=5\left[(J j \Delta t)^{4}-8(j \Delta t)^{3}+26(j \Delta t)^{2}-32 \cdot j \Delta t+13\right]
$$

よって

$$
\min J\left(u_{1, j}\right)=0 \text { at } j \Delta t=1.0
$$

を得る.したがって $u_{2}(t)$ は $t=1.0$ で切換わるバン グーバング制御となり，これが求める最適制御関 数で ある・

同じ例題を計算機 (FACOM 230-60) で解いた。微 分方程式はすべて RKG 法で解いた. $0 \leqq t \leqq 2.0$ を 100 きざみで行なった. 結果は上述したものとまった く同じ結果が得られ，計算時間は約 18 秒であった.

\section{$6 \cdot 2$ 例題 2 (Jacobson の例題 $)^{4)}$}

制御対象の運動方程式は,

$$
\left.\begin{array}{l}
\dot{x}_{1}=-0.5 x_{1}+5 x_{2} \\
\dot{x}_{2}=-5 x_{1}-0.5 x_{2}+u \\
\dot{x}_{3}=-0.6 x_{3}+10 x_{4} \\
\dot{x}_{4}=-10 x_{3}-0.6 x_{4}+u
\end{array}\right\}
$$

で表わされ， $u$ には $|u| \leqq 1$ なる制限がある。終端条 件は,

$$
t_{f}=4.2, x_{i}\left(t_{f}\right): \text { 自由 } i=1,2,3,4
$$

評洒関数は,

$$
J=x_{1}{ }^{2}\left(t_{f}\right)+x_{2}{ }^{2}\left(t_{f}\right)+x_{3}{ }^{2}\left(t_{f}\right)+x_{4}{ }^{2}\left(t_{f}\right)
$$


で与えられる. 初期条件 $x_{1}(0)=10.0, x_{2}(0)=10.0$, $x_{3}(0)=10.0, x_{4}(0)=10.0$ から出発する解を求める.

制御 $u$ の最初の推定を $u(t)=1.0,0 \leqq t \leqq 4.2$ で与 える.この計算も FACOM 230-60 で行なった. 微分 方程式は RKG 法を用いて解いた. 区間 $0 \leqq t \leqq 4.2$ を 300 きざみにした．評価関数值の変化を Fig. 4 に 示す. Fig. 5 に得光られた最適制御関数とそのとき

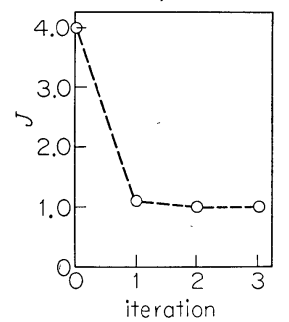

Fig. 4 Cost versus iteration in example 2

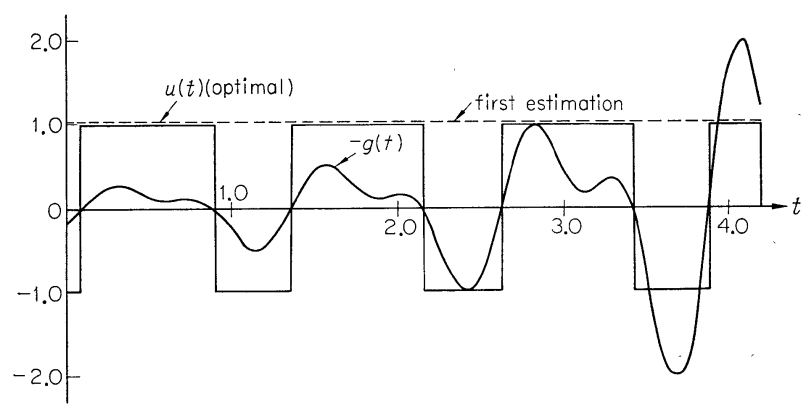

Fig. 5 Optimal control $u(t)$ and $-g(t)$ in example 2

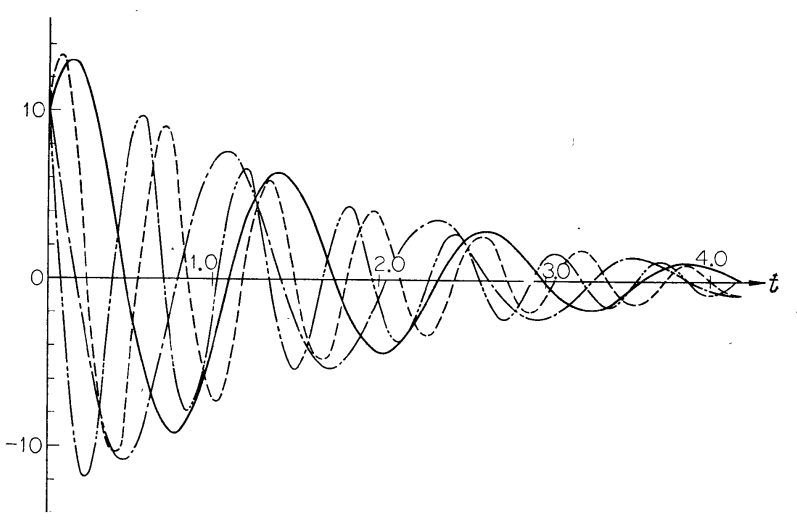

$-: x_{1}(t) \quad---: x_{2}(t) \quad-\cdot-: x_{3}(t) \quad-\cdots-: x_{4}(t)$

Fig. 6 Time sequence of state point in example 2
の $-g(t)$ を示す. これより, この最適制御 関数と $-g(t)$ は (21) 式の局所的最適条件を満足しているこ とがわかる. Fig. 6 に状態点の変化を示す.な扣計 算時間は 174 秒であった。

\section{7. あとがき}

こう配関数を用いて最適バングーバング制御関数を 求めるアルゴリズムを提案した，そのために，まず仮 定した $u(t)$ がバングーバング形の関数である場合のこ う配関数を導びいた.ささらに共状態ベクトルを微分方 程式の解として求めることによって，このこう配関数 が容易に計算されることを示した．例題によってこの アルゴリズムの有効性を調べた. その結果このアルゴ リズムは，かなり有効なものと思われる．今後この手 法を最短時間問題に適用することを考えたい.

\section{参 考 文 献}

1) L. W.Neustadet:Synthesizing Time Optimal Control System, Jr. MAAA 1, 483/493(1960)

2) J.H. Eaton : A Iteratiue Solution to TimeOptimal Control, Jr. MAAA 5, 329/344 (1962)

3）山口化雄：パルス摄動による最短間時制御の 計算, 計測自動制御学会論文集, 3-3, 181/187 (1967)

4) D. H. Jacobson : Differential Dynamic Programming Method for Solving Bang-Bang Control Problems, IEEE AC-13-6, 661/675. (1968)

5) H. J. Kelley : Method of Gradient in Optimization Technique (book) ed. by G. Leitmann, Academic Press (1962)

6）市川・田村：こう配法による最適制御問 題の 解法, 計測と制御, 8-11，761/777 (1969)

7) L.S. Lasdon, S. K. Mitter and A.D. Waren : The Conjugate Gradient Method for Optimal Control Problems, IEEE, AC-12-2, 132/138 (1967)

8）市川・田村：最適制御関数を求めるアルゴリ ズム（II），第 8 回計測自動制御学会学術講演 会 (1969)

9) Pontryagin and et al. : The Mathematical Theory of Optimal Processes, John Wiley and Sons (1962)

10） ポソトリヤーギン：常微分方程式, 共立出版, 173/177 (1963)

11) E. A. Coddington and N. Levinson : Theory of Ordinary Differential Equations, McGraw-Hill, p. 67 (1955)

12) A.E.Bryson and Y.C.Ho: Applied Optimal Control, Blaisdell Publishing Company, p. 104/110 (1969) 